\title{
2D Temperature Detection Characteristics of Engine Exhaust Gases Using CT Tunable Diode Laser Absorption Spectroscopy
}

\section{Takahiro Kamimoto and Yoshihiro Deguchi*}

Graduate School of Advanced Technology and Science, Tokushima University, 2-1, Minamijyosanjima, Tokushima, 770-8506 Japan

\section{Abstract}

Two dimensional (2D) temperature and concentration distribution is related to the combustion structure, the combustor efficiency in engines, burners, gas turbines and so on. Recently, tunable diode laser absorption spectroscopy (TDLAS) as a multi-species measurement technique with high sensitivity and high response has been developed and applied to industrial process monitoring and control technologies in combustion environments. With these engineering developments, transient phenomena such as start-ups and load changes in engines have been gradually elucidated in various conditions. This paper discusses a study of the fast response 2D temperature distribution measurement method based on the combination of TDLAS and Computed Tomographic (CT) reconstruction using absorption spectra of water vapor at $1388 \mathrm{~nm}$. The computed tomography tunable diode laser absorption spectroscopy (CTTDLAS)method was appliedtoengine exhausts for 2D temperature distribution measurements. The measured 2D temperature showed better characteristics compared with the temperature measured by a thermocouple. Theoretical $\mathrm{H}_{2} \mathrm{O}$ absorption spectra in the $1388 \mathrm{~nm}$ near-infrared region calculated by the revised HITRAN database were used for temperature measurement. For accurate measurement of temperature in combustion gases, the spectroscopic databases were modified using experimentally measured spectral parameters that are not found in the databases. Accuracy of temperature measurement using TDLAS have also been discussed to demonstrate its applicability to various types of combustor.
\end{abstract}

\section{Introduction}

Improvements in combustion efficiencies and reduction in harmful combustion emissions such as $\mathrm{NOx}, \mathrm{CO}$ and particles in engines, burners, gas turbines and so on are important for our lives and the science development. It can be accomplished by measuring and controlling the important combustion parameters such as temperature and species concentration. Conventionally a thermocouple and a sampling probe have been widely used as a temperature and concentration measurement devices. However it is intrinsically a point measurement methodand it is difficult to measure temperature and concentration distributions inside the combustion chamber and exhaust with sufficient time resolution. Compared to the point measurement, combustion chamber designs and fuelling strategies can be efficiently evaluated by visualizing two dimensional(2D) temperature and concentration distributions, which have effects on complex phenomena such as knocking, combustion instability and production of pollutants in combustors. Therefore, 2D temperature and concentration distribution plays an important role for the combustion structure, the combustion efficiency and reduction of pollutants including $\mathrm{NOx}, \mathrm{CO}$ and particles in engines, burners, gas turbines and so on.

Recently, tunable diode laser absorption spectroscopy (TDLAS) as a for temperature and species concentration measurement technique with high sensitivity and high response in combustion environments has been researched and applied to the actual combustors [112]. With these engineering developments, transient phenomena such as start-ups and load changes in engines have been gradually elucidated in various conditions [3]. This paper discusses a study of the fast response $2 \mathrm{D}$ temperature and concentration distribution measurement method based on the combination of TDLAS and Computed Tomographic (CT) reconstruction using absorption spectra of water vapor at $1388 \mathrm{~nm}$. The computed tomography tunable diode laser absorption spectroscopy (CT-TDLAS)method[13-17] was applied to engine exhausts for $2 \mathrm{D}$ temperature distribution measurement. Theoretical $\mathrm{H}_{2} \mathrm{O}$ absorption spectra in the $1388 \mathrm{~nm}$ near-infrared region calculated by the revised HITRAN database were used for temperature measurement. It is important to test the spectral parameters under high temperature conditions to evaluate quantitative measurements of temperature and species concentration. Accuracy of temperature measurement using TDLAS have also been validated to demonstrate its applicability to various types of combustor.

\section{Theory}

The gas temperature and species concentration measurement method using near infrared tunable diode laser absorption spectroscopy (TDLAS) was used in this research. TDLAS is a multispecies measurement technique with high sensitivity and high response by continuously scanning laser wavelengths and measuring absorption spectra of selected gases. Principle of TDLAS is based on Lambert Beer's law. When a beam of laser diode is transmittedacross the measurement area containing target gases, the strength of the permeated light is related to absorber concentration according to Lambert Beer's law. TDLAS depends on this spectroscopic principles to continuously measure temperature and species concentration of selected gases. The number density of the measured species $\mathrm{n}$ is related to the amount of light absorbed as in the following formula [1]:

$$
I_{\lambda} / I_{\lambda 0}=\exp \left\{-A_{\lambda}\right\}=\exp \left\{-\sum_{i}\left(n_{i} L \sum_{i} S_{i, j}(T) G_{V i, j}\right)\right\}
$$

Here, $I_{\lambda 0}$ is the incident light intensity, $I_{\lambda}$ the transmitted light intensity, $A_{\lambda}$ the absorbance, $n_{i}$ the number density of species $i, L$ the "Corresponding Author: Dr. Yoshihiro Deguchi, Graduate School of Advanced Technology and Science, Tokushima University, 2-1, Minamijyosanjima, Tokushima, 770-8506 Japan; E-mail: ydeguchi@tokushima-u.ac.jp

Citation: Kamimoto T, Deguchi Y (2015) 2D Temperature Detection Characteristics of Engine Exhaust Gases Using CT Tunable Diode Laser Absorption Spectroscopy. Int J Mech Syst Eng 1: 109. doi: http://dx.doi. org/10.15344/2455-7412/2015/109

Copyright: () 2015 Kamimoto et al. This is an open-access article distributed under the terms of the Creative Commons Attribution License, which permits unrestricted use, distribution, and reproduction in any medium, provided the original author and source are credited. 
Citation: Kamimoto T, Deguchi Y (2015) 2D Temperature Detection Characteristics of Engine Exhaust Gases Using CT Tunable Diode Laser Absorption Spectroscopy. Int J Mech Syst Eng 1: 109. doi: http://dx.doi.org/10.15344/2455-7412/2015/109

Page 2 of 7

path length, $S_{i, j}$ the temperature dependent absorption line strength of the absorption line $j$, and $G_{v i j}$ the line broadening function.

In this study $\mathrm{H}_{2} \mathrm{O}$ absorption spectra in the $1388 \mathrm{~nm}$ near-infrared region were used for sensitive measurement of temperature in combustion environments. Theoretical $\mathrm{H}_{2} \mathrm{O}$ absorption spectra in the $1388 \mathrm{~nm}$ near-infrared region calculated by the HITRAN database [18] are shown in Figure 1. Three absorption lines located at $1388.135 \mathrm{~nm}(\# 1), 1388.326 \mathrm{~nm}(\# 2)$, and $1388.454 \mathrm{~nm}(\# 3)$ have remarkable temperature dependence were chosen to measure temperature. It is important to use several absorption lines with different temperature dependence to reduce the temperature error induced by a CT algorism. When several laser beamsare transmitted across the measurement area containing a target gas as shown Figure 2 , integrated absorbance of each laser path is related to the absorber temperature and concentration distribution along the path as in the following formula [13-17]:

$$
A_{\lambda, P}=\sum_{q} n_{q} L_{p, q} \alpha_{\lambda, q}
$$
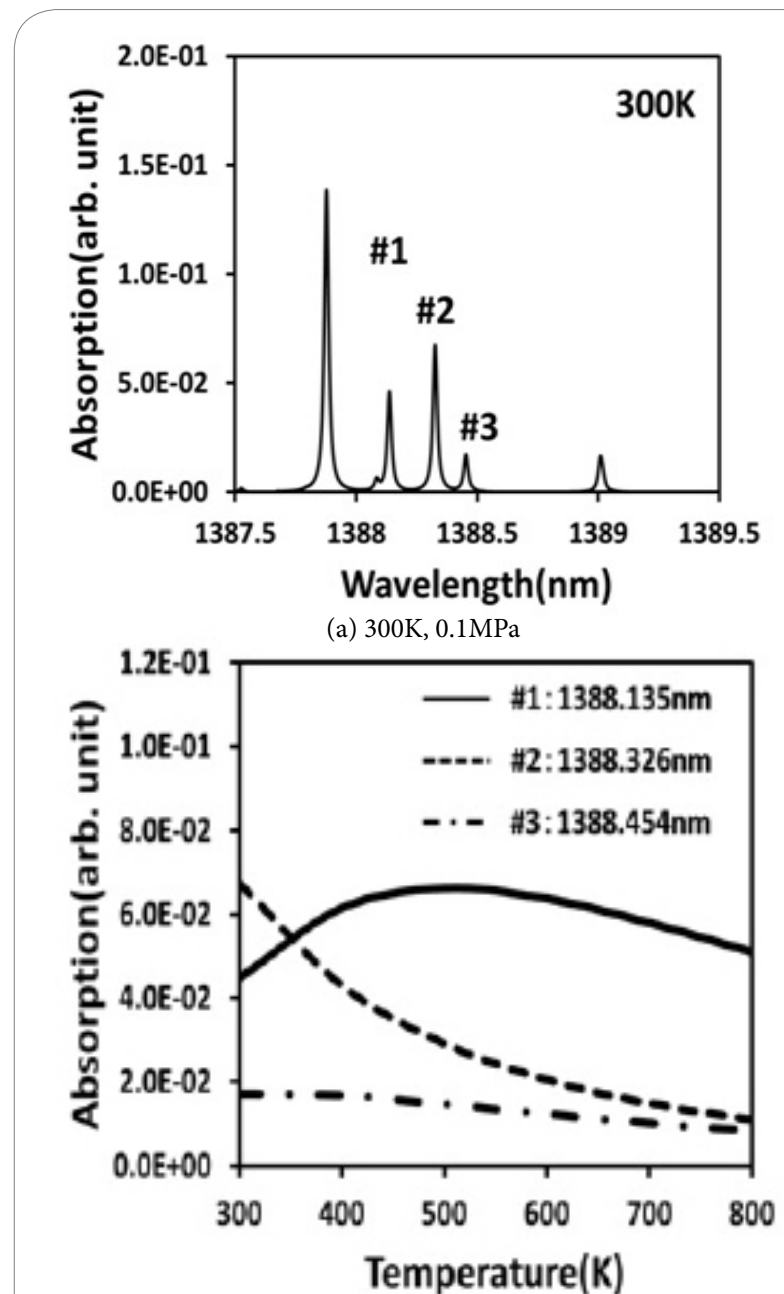

(c) Temperature dependence intensity ratio of three absorption lines.

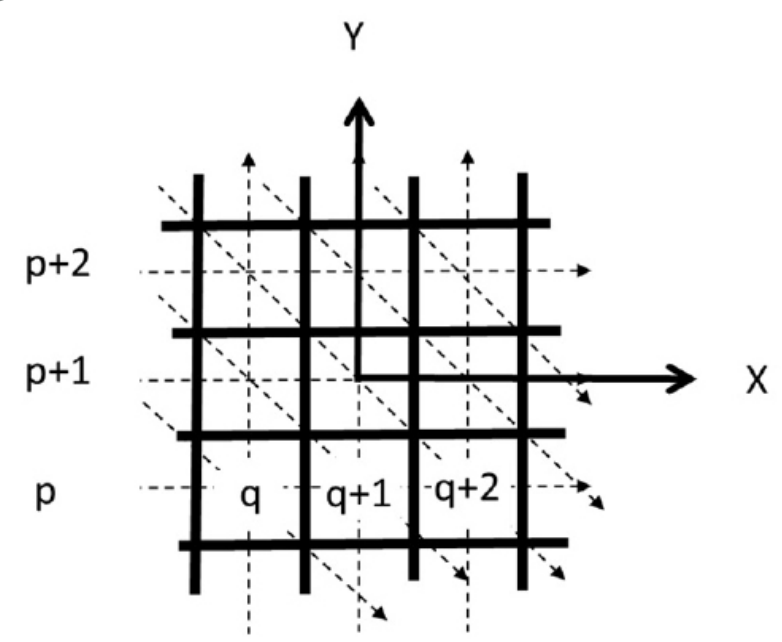

Figure 2: CT grid and laser path.
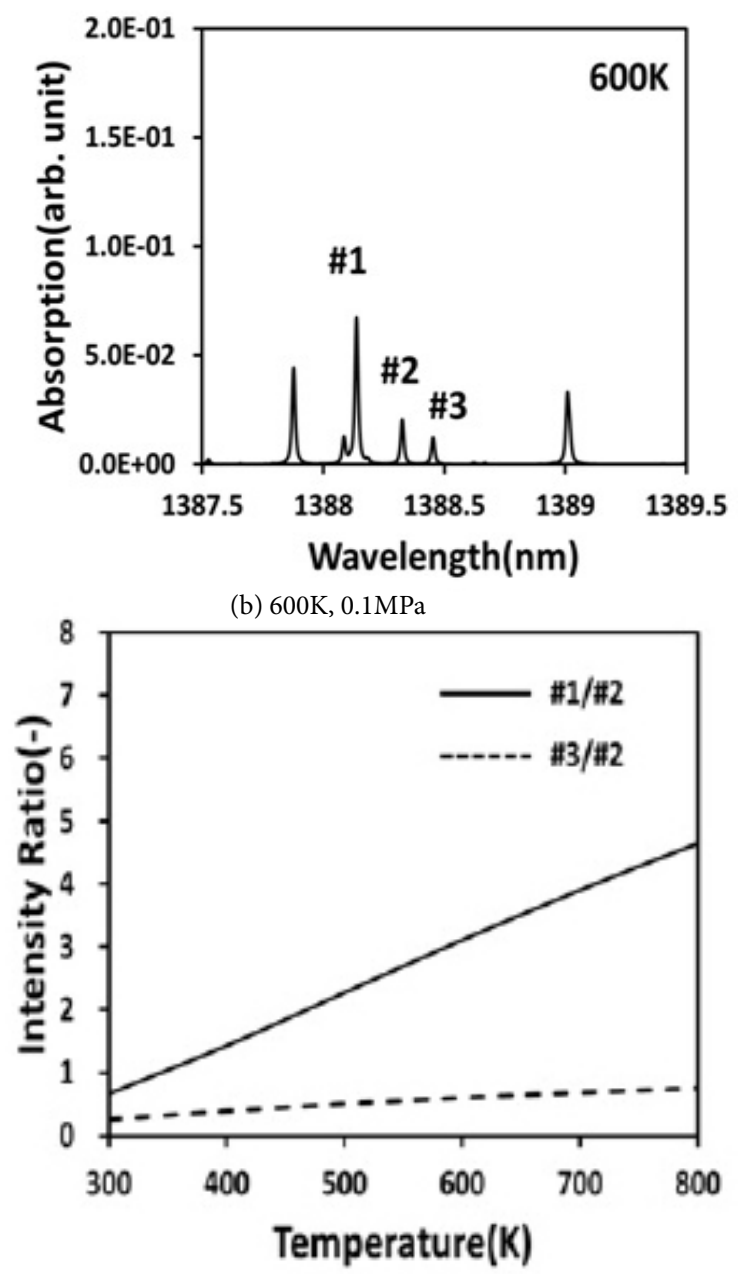

(d) Temperature dependence intensity ratio of two absorption lines

Figure 1: Theoretical $\mathrm{H}_{2} \mathrm{O}$ absorption spectra (\#1:1388.135nm, \#2:1388.326nm, \#3:1388.454nm).

Here, $A_{\lambda, p}$ is integrated absorbance of some wavelength $\lambda$ in a path, $\alpha_{\lambda, q}$ is absorption coefficient of some wavelength $\lambda$ inside a grid $q$ on the path and is depend on temperature and density of species. $L_{p, q}$ is path length inside the grid $\mathrm{q}$.
Temperature and $\mathrm{H}_{2} \mathrm{O}$ concentration at each analysis grid were determined using a multifunction minimization method[19] to minimize the spectral fitting error at 1338.0-1338.6 nm.Sets of $\mathrm{H}_{2} \mathrm{O}$ densities and temperatures at analysis grids are obtainedby the best-fitted distributions for a given measurement of $A_{\lambda}$, pusing the 
Citation: Kamimoto T, Deguchi Y (2015) 2D Temperature Detection Characteristics of Engine Exhaust Gases Using CT Tunable Diode Laser Absorption Spectroscopy. Int J Mech Syst Eng 1: 109. doi: http://dx.doi.org/10.15344/2455-7412/2015/109

Page 3 of 7

minimization procedure shown in Figure 3. A set of measured $\mathrm{H}_{2} \mathrm{O}$ absorption spectra was compared to the theoretical spectra to minimize the mean squared errors.

Error $=\sum\left\{\left(A_{\lambda, q}\right)_{\text {theory }}-\left(A_{\lambda, q}\right)_{\text {experiment }}\right\}^{2}$
(NTT Electronics Co., NLK1E5GAAA) at $1388 \mathrm{~nm}$ with scanning range of $0.6 \mathrm{~nm}$ was used to measure water vapor absorption spectra. The lasers were scanned at $1 \mathrm{kHz}$ and these outputs were mixed using a fiber combiner. Absorption spectra were simultaneously measured to

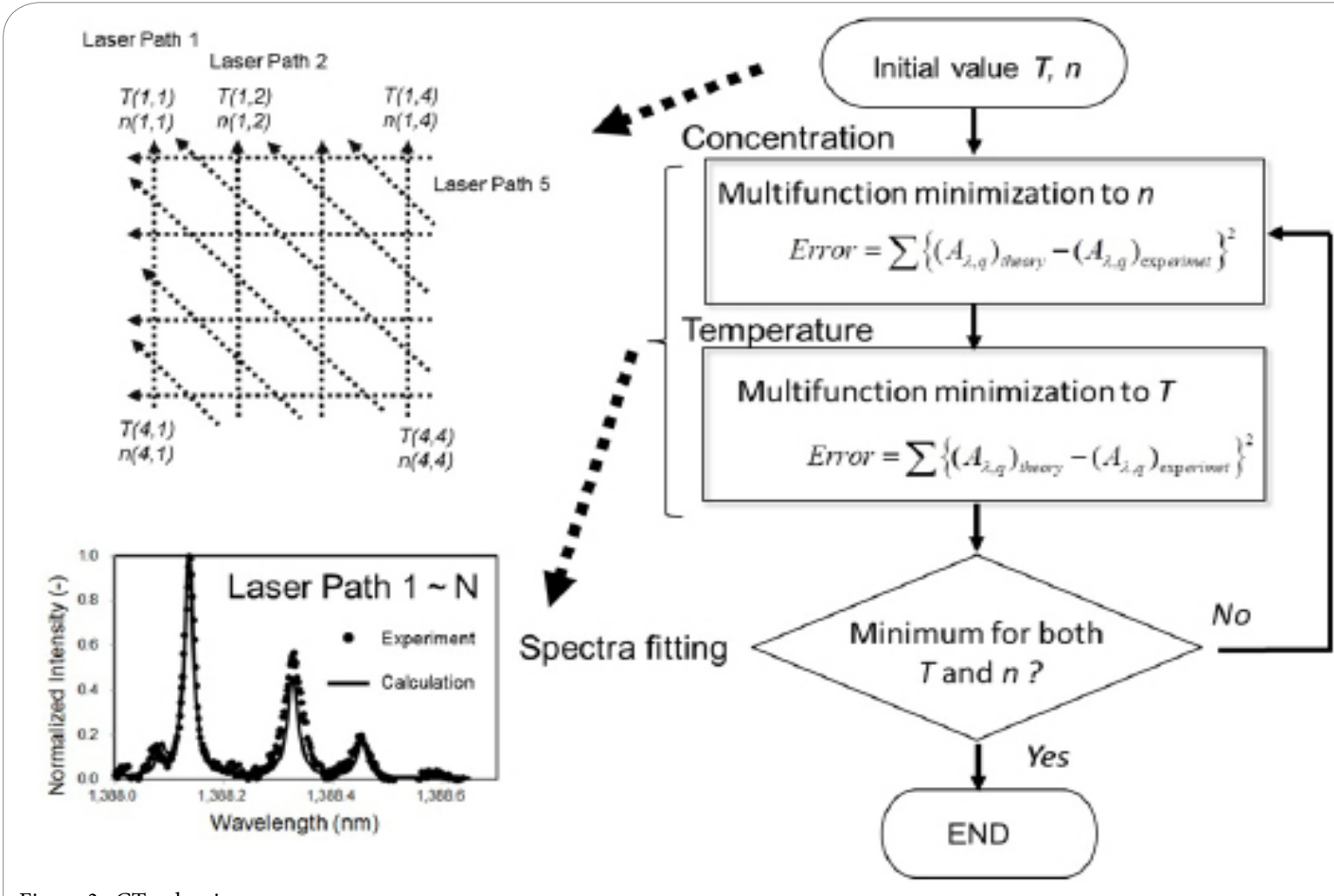

Figure 3: CT -algorism.

A polynomial noise reduction technique $[14,15]$ was also used to reduce noises such as the effect of laser beam steering.

\section{Experiment}

\section{Evaluation of temperature measurement accuracy}

Tunable diode laser absorption spectroscopies (TDLAS) of $\mathrm{H}_{2} \mathrm{O}$ in a heated cell were used to obtain the spectroscopic data and improve temperature measurement accuracy. Figure 4 shows the experimental setup for $\mathrm{H}_{2} \mathrm{O}$ absorption spectra measurements from $300 \mathrm{~K}$ to $800 \mathrm{~K}$ using TDLAS. A distributed feedback(DFB)diode laser (NTT Electronics Co., NLK1E5GAAA) at $1388 \mathrm{~nm}$ was used for obtaining $\mathrm{H} 2 \mathrm{O}$ absorption spectra at $1388-1388.6 \mathrm{~nm}$. The laser was driven with diode laser controller (Thorlabs Co., TXP5004) with current source and temperature-control units (Thorlabs Co., ITC5052). Wavelength modulation was consisted of $5 \mathrm{kHz}$ saw tooth ramp, which has better wavelength linearity for spectral evaluation than sinusoidal modulation, using a function generator (Wave factory Co., WF1946). The laser beam was irradiated into the measurement cell using a collimator (THORLABS Co., 50-1310-APC). The transmitted light intensities were detected by a photodiode (Hamamatsu Photonics and G8370-01). The photodiode signal was amplified by an amplifier (Stanford Research Systems, SR445A) and directly stored by a recorder (HIOKI E.E. Co., 8861 Memory High coda HD Analog16).

2D temperature measurements in engine exhausts using CTTDLAS

Figure 5 shows the outline of an experimental apparatus of the 2D temperature measurement used in this study. A DFB laser calculate the instant 2D temperature using 16 path measurement cells shown in Figure 5. The laser beam was separated by an optical fiber splitter (OPNETI CO., SMF-28e 1310nm SWBC $1 \times 16$ ) and the separated laser beams were irradiated into the target area by 16 collimators (THORLABS Co., 50-1310-APC). The transmitted light intensities were detected by photodiodes (Hamamatsu Photonics and G8370-01), and taken into the recorder (HIOKI E.E. Co., 8861 Memory Highcoda HD Analog16). The data acquisition rate was $500 \mathrm{kHz}$ (500 data points on every 1 scan of absorption spectra). Temperature in the measurement region was also measured by chromel-alumel thermocouples with a diameter of $100 \mu \mathrm{m}$ (KMT100-100-120).

2D temperature measurements in engine exhausts using CTTDLAS were performed using a gasoline engine (FUJI HEAVY INDUSTRIES, Inc., EX13) as shown in Figure 6. The laser paths were set at the position $5 \mathrm{~mm}$ above the outlet of the engine exhaust pipes. The diameter of 16 path measurement cell was $70 \mathrm{~mm}$. The diameter of the engine exhaust pipe is $22 \mathrm{~mm}$ with thickness of $3.5 \mathrm{~mm}$ and the pipe length was $160 \mathrm{~mm}$.

\section{Results and Discussion}

\section{Evaluation of temperature measurement accuracy}

In this study three absorption lines located at $1388.135 \mathrm{~nm}(\# 1)$, $1388.326 \mathrm{~nm}(\# 2)$, and $1388.454 \mathrm{~nm}(\# 3)$ were chosen to measure temperature and $\mathrm{H}_{2} \mathrm{O}$ concentration. Absorption spectra of $\mathrm{H}_{2} \mathrm{O}$ at $1388-1388.6 \mathrm{~nm}$ in the heated cell were measured by TDLAS. Figure 7 shows absorption spectra of $\mathrm{H}_{2} \mathrm{O}$ at $400 \mathrm{~K}$ and $800 \mathrm{~K}$ measured by 
Citation: Kamimoto T, Deguchi Y (2015) 2D Temperature Detection Characteristics of Engine Exhaust Gases Using CT Tunable Diode Laser Absorption Spectroscopy. Int J Mech Syst Eng 1: 109. doi: http://dx.doi.org/10.15344/2455-7412/2015/109

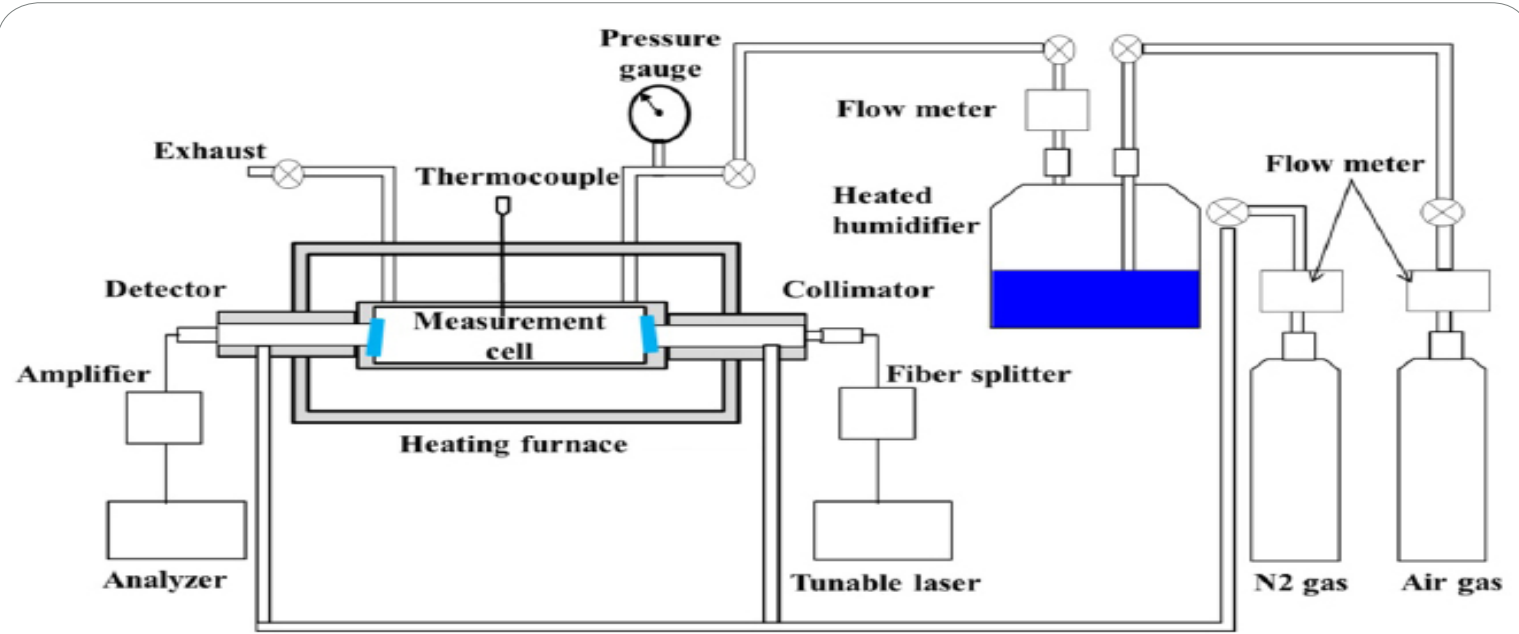

Figure 4: Experimental apparatus for evaluation of temperature measurement accuracy.

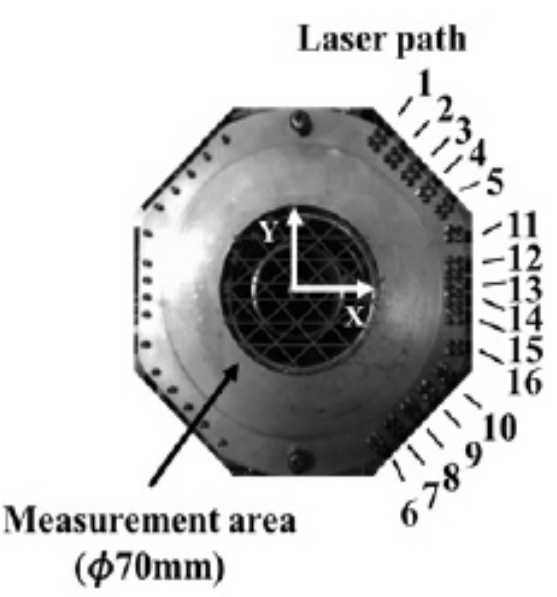

Figure 5: 16 path CT-TDLAS measurement cell.

\section{Tunable laser}

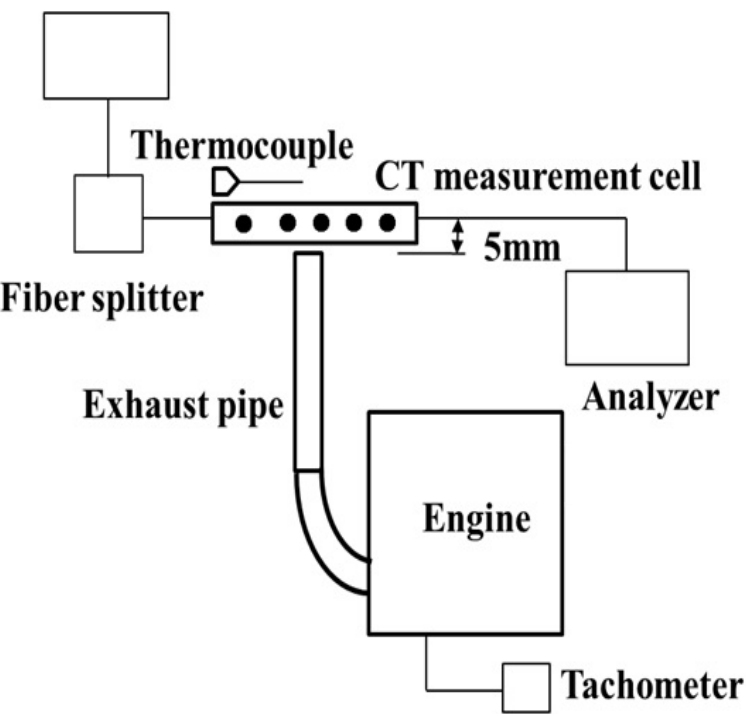

Figure 6: Engine experiment.

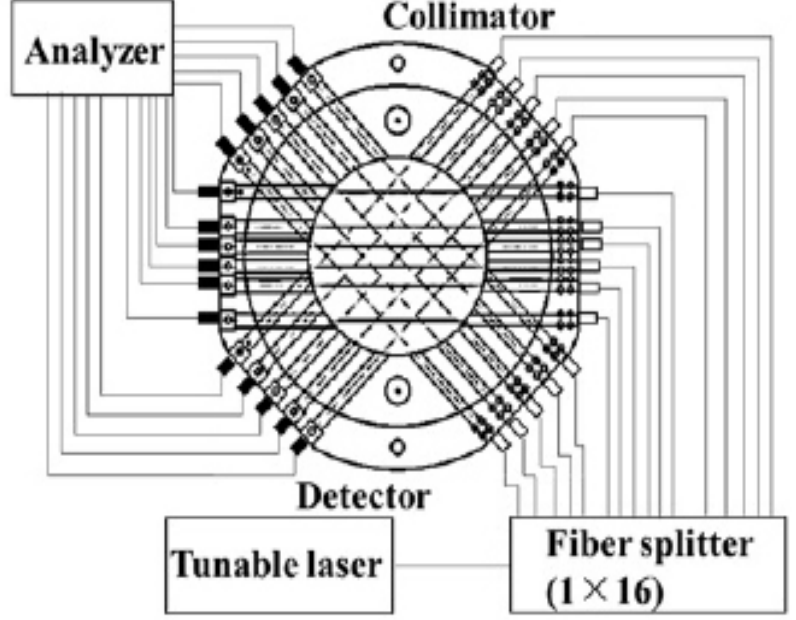

TDLAS and they are compared with corrected theoretical spectra. The theoretical absorption spectra of $\mathrm{H}_{2} \mathrm{O}$ were revised by the measured spectralparameters, which include the set of temperature dependent absorption line strength $\left(S_{i, j}(T)\right)$ between 1388-1388.6nm. The corrected theoretical spectra showed good agreement with measurement results as shown Figure 8. Figure 9 shows comparison of measured temperature between TDLAS and thermocouple. Improved agreement of measured temperature between TDLAS and thermocouple was obtained using corrected spectroscopic data. It is worth to mention that the revision of the spectroscopic database leads to better temperature measurement accuracy.

2D temperature measurements in engine exhausts using CTTDLAS

CT measurement cell was applied to engine exhausts. The center of an exhaust outlet was set at the center of the CT measurement cell. The exhaust gas temperature distribution was measured by CT tunable diode laser absorption spectroscopy (CT-TDLAS). The exhaust gas temperature at $\mathrm{X}=0 \mathrm{~mm}, \mathrm{Y}=0 \mathrm{~mm}$ was simultaneously measured by a thermocouple. Figure 10 shows the temperature history measured by the thermocouple at $\mathrm{X}=\mathrm{Y}=0 \mathrm{~mm}$, averaged temperature of the laser path 6 and 8, and engine rotation speed. The engine was started at $\mathrm{t}=0 \mathrm{~s}$ and the engine revolution was increased up to $2500 \mathrm{rpm}$. In this 
Citation: Kamimoto T, Deguchi Y (2015) 2D Temperature Detection Characteristics of Engine Exhaust Gases Using CT Tunable Diode Laser Absorption Spectroscopy. Int J Mech Syst Eng 1: 109. doi: http://dx.doi.org/10.15344/2455-7412/2015/109

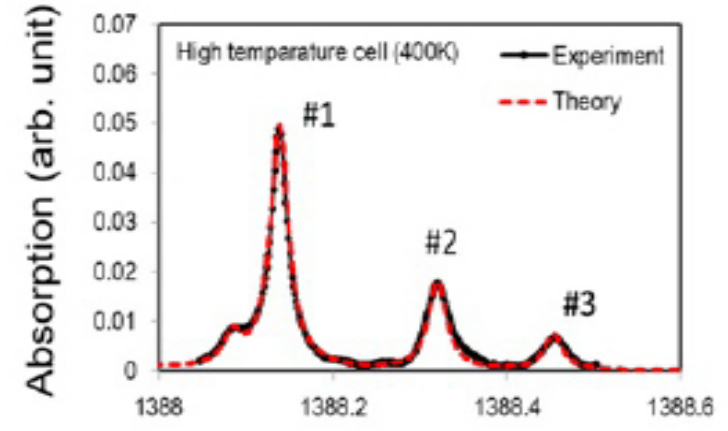

(a) $400 \mathrm{~K}$

Wavelength $(\mathrm{nm})$

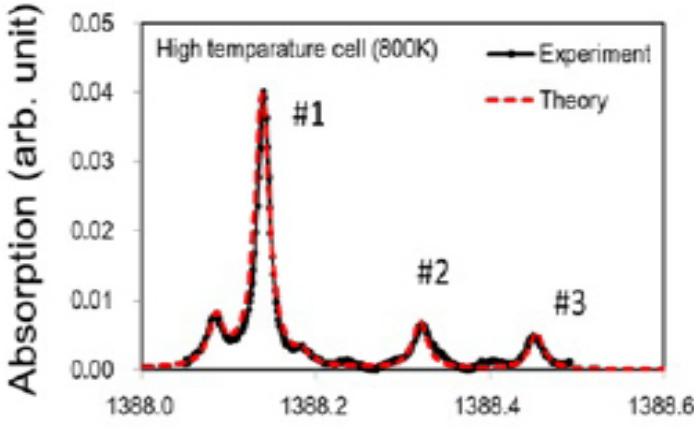

(b) $800 \mathrm{~K}$
Wavelength $(\mathrm{nm})$

Figure 7: Experimental and theoretical absorption spectra of $\mathrm{H}_{2} \mathrm{O}$ at $400 \mathrm{~K}$ and $800 \mathrm{~K}$ using corrected spectroscopic database(\#1:1388.135nm, \#2:1388.326nm, \#3:1388.454nm).

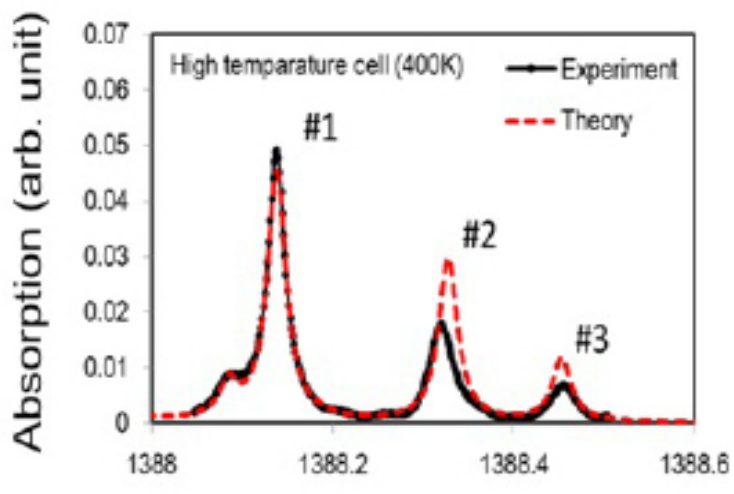

(a) Uncorrected Wavelength ( $\mathrm{nm}$ )

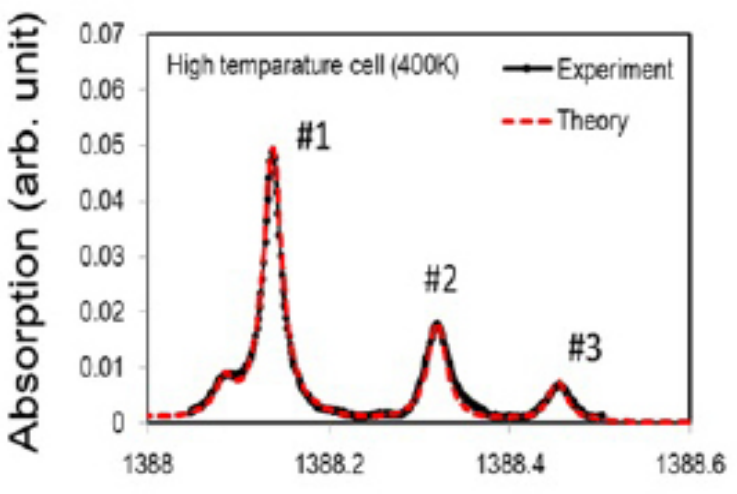

(b) Corrected Wavelength (nm)

Figure 8: Theoretical $\mathrm{H}_{2} \mathrm{O}$ absorption spectra (\#1:1388.135nm, \#2:1388.326nm, \#3:1388.454nm) using uncorrected and corrected spectroscopic database

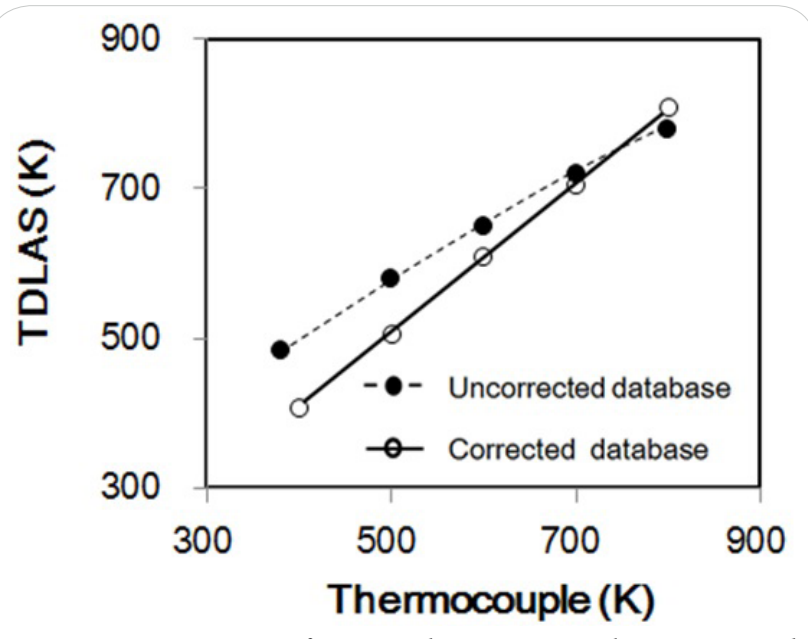

Figure 9: Comparison of measured temperatures by TDLAS and thermocouple.

experiment, $1388.135 \mathrm{~nm}(\# 1), 1388.326 \mathrm{~nm}(\# 2)$, and 1388.454 $\mathrm{nm}$ (\#3) absorption lines were used to measure the exhaust gas temperature. The temperature of exhausts showed sharp peaks attributed to the engine cycle. The temperature measured by the thermocouple showed the temporally delayed and smoothed time history caused by the low response. The TDLAS measurement results also showed the unburned cycles at $1100 \mathrm{~ms}, 1250 \mathrm{~ms}$, and $2900 \mathrm{~ms}$, and $3000 \mathrm{~ms}$.
Figure 11 show the 2D temperature measurement results in engine exhausts. The results showed high temperature area at the center of the exhaust pipe and temperature distribution was a rapid change according to the engine evolution. The rapid $2 \mathrm{D}$ temperature measurement in engine exhaust using CT-TDLAS successfully demonstrated the merit of this technique for practical diagnostic use, including high temperature and pressure area such as internal combustion engine.

In high temperature (1000-2000 K) and pressure (1-5MPa) fields such as the temperature distribution in combustion chambers of an standard vehicle engine, the spectral parameters under these conditions to evaluate quantitative measurements of temperature and species concentration will be important.

\section{Conclusion}

2D Temperature detection characteristics of engine exhausts using CT tunable diode 1 Laser absorption spectroscopy were investigated. Based on the results of this study, the following conclusions are summarized as follows.

1. Theoretical absorption spectra calculated by HITRAN database showed several discrepancies between measured and calculated spectra. The revision of the spectroscopic data leads to better measurement accuracy.

2. The $2 \mathrm{D}$ temperature measurement method using CT tunable diode laser absorption spectroscopy was developed and 
Citation: Kamimoto T, Deguchi Y (2015) 2D Temperature Detection Characteristics of Engine Exhaust Gases Using CT Tunable Diode Laser Absorption Spectroscopy. Int J Mech Syst Eng 1: 109. doi: http://dx.doi.org/10.15344/2455-7412/2015/109

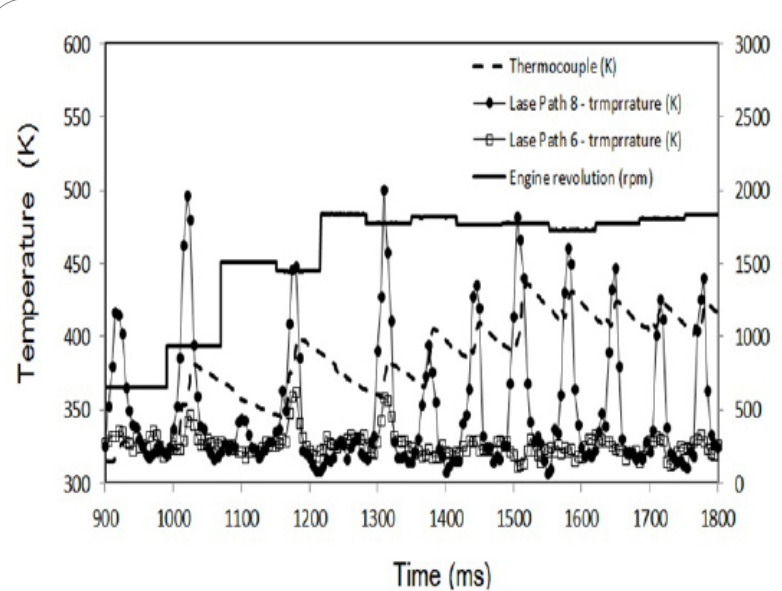

(a) $900-1800 \mathrm{~ms}$ after the engine start

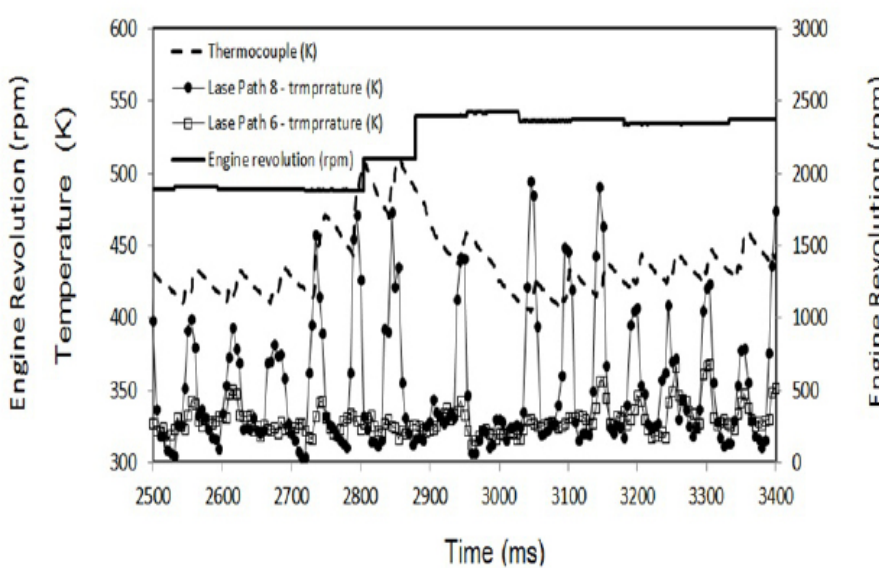

(b) $900-1800 \mathrm{~ms}$ after the engine start

Figure 10: Average temperature of laser path 6 and 8 measured by tunable diode laser absorption spectroscopy.

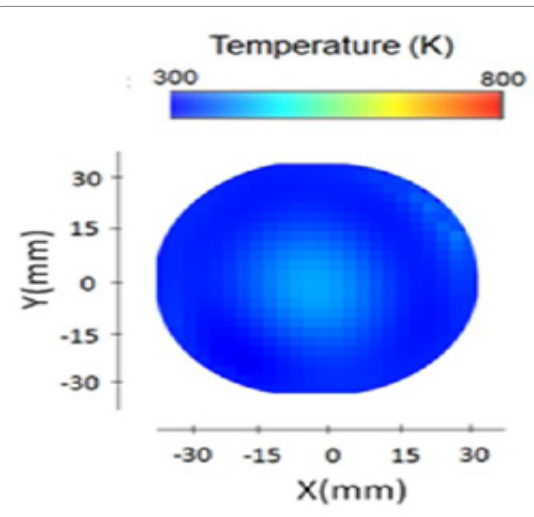

(a) $\mathrm{t}=1000 \mathrm{~ms}$

Temperature (K)

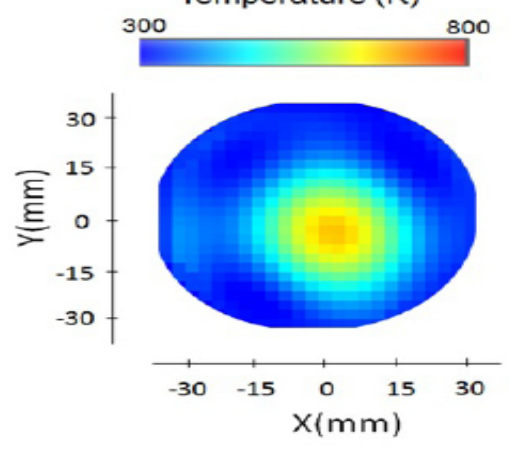

(d) $\mathrm{t}=1015 \mathrm{~ms}$

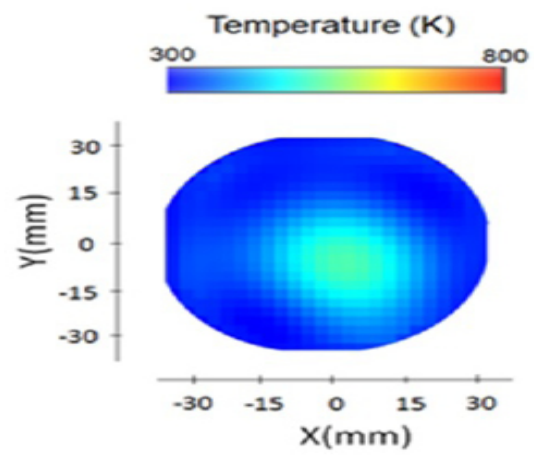

(g) $\mathrm{t}=1030 \mathrm{~ms}$

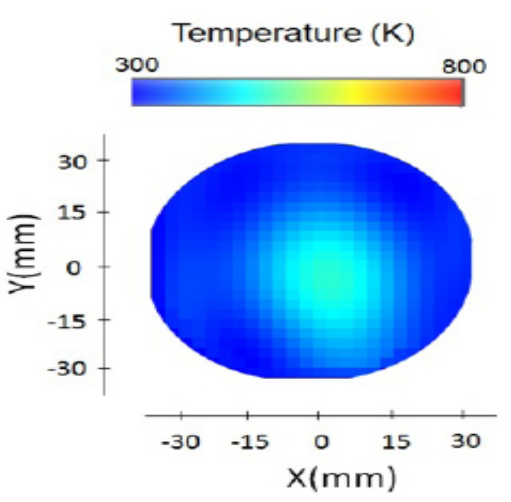

(b) $\mathrm{t}=1005 \mathrm{~ms}$

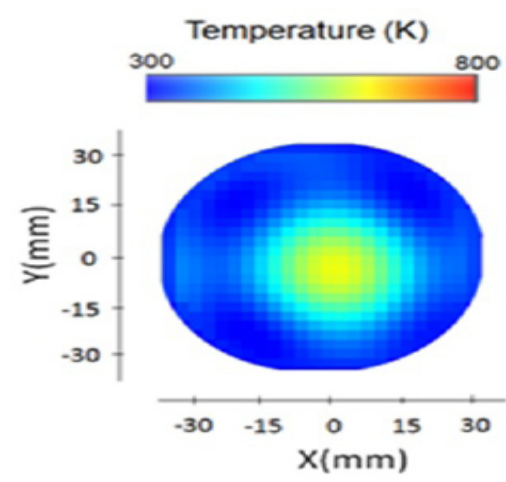

(e) $\mathrm{t}=1020 \mathrm{~ms}$

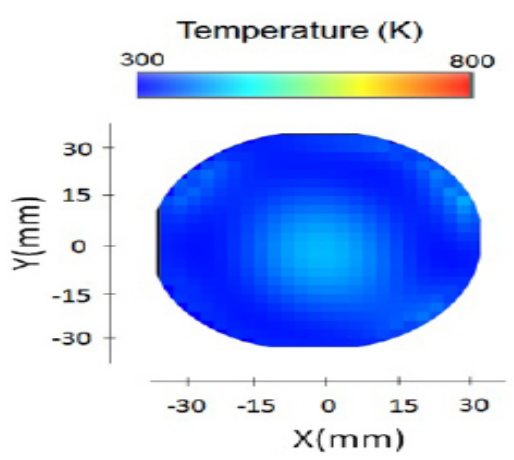

(h) $\mathrm{t}=1035 \mathrm{~ms}$

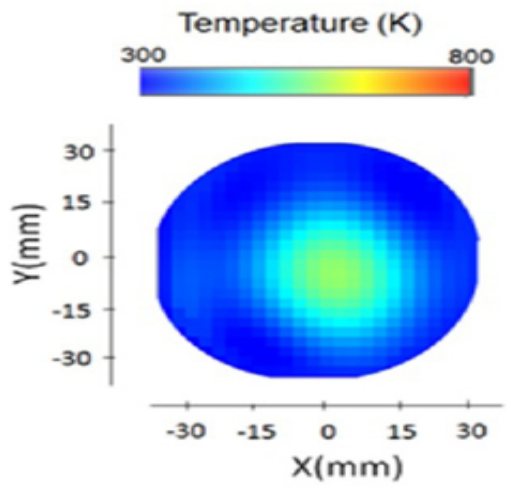

(c) $\mathrm{t}=1010 \mathrm{~ms}$

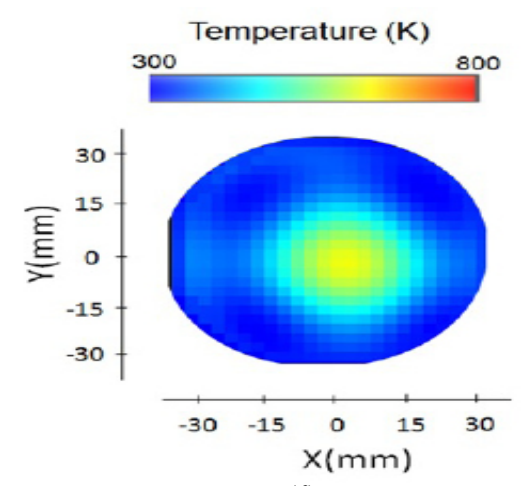

(f) $\mathrm{t}=1025 \mathrm{~ms}$

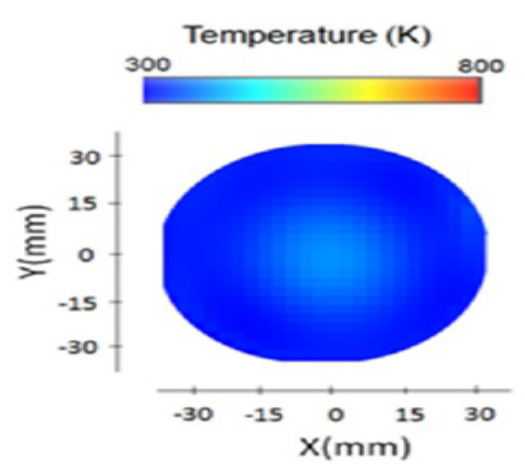

(i) $\mathrm{t}=1040 \mathrm{~ms}$

Figure11: 2D Temperature measurement results in engine exhausts using 16 path measurement cells. 
Citation: Kamimoto T, Deguchi Y (2015) 2D Temperature Detection Characteristics of Engine Exhaust Gases Using CT Tunable Diode Laser Absorption Spectroscopy. Int J Mech Syst Eng 1: 109. doi: http://dx.doi.org/10.15344/2455-7412/2015/109

successfully demonstrated to measure $2 \mathrm{D}$ temperature distributions in engine exhausts using 16 path measurement cells. It was demonstrated that time-resolved 2D temperatures using CT tunable diode laser absorption spectroscopy in engine exhausts was achieved for practical applications.

\section{Competing Interests}

The authors have no competing interests with the work presented in this manuscript.

\section{Author Contributions}

All authors contributed significantly to this work. Yoshihiro Deguchi proposed and conceived the study. Yoshihiro Deguchi made substantial contribution to design and guide the experiment. Takahiro Kamimoto performed the experiment, analyzed data and wrote the manuscript. All authors participated in drafting the article and revising it critically. All authors read and approved the final manuscript.

\section{References}

1. Deguchi $Y,(2011)$ Industrial applications of Laser Diagnostics, CRS Press: Taylor \& Francis

2. Zaatar Y, Bechara J, Khoury A, Zaouk D, Charles J-P (2000) Diode laser sensor for process control and environmental monitoring. Applied Energy 65: 107-113.

3. Yamakage M, Muta K, Deguchi Y, Fukada S, Iwase T, et al. (2008) Development of Direct and Fast Response Exhaust Gas Measurement SAE Paper 20081298.

4. Morthier G, Vankwikelberge P (2013) Handbook of Distributed Feedback Laser Diodes, Artech House Applied Photonics.

5. Yariv A, Yeh P (2006) Photonics: Optical Electronics in Modern Communications, Oxford Univ Press.

6. Kranendonk LA, Walewski JW, Kim T, Sanders ST, et al. (2005) Wavelengthagile sensor applied for $\mathrm{HCCl}$ engine measurement. Proceedings of the Combustion Institute 30: 1619-1627.

7. Rieker GB, Li H, Liu X, Liu JTC, Jeffries JB, et al. (2007) Rapid measurements of temperature and $\mathrm{H}_{2} \mathrm{O}$ concentration in IC engines with a spark plug-mounted diode laser sensor. Proceedings of the Combustion Institute 31: 3041-3049.

8. Liu X, Jeffries JB, Hanson RK, Hinckley KM, Woodmansee MA (2006) Development of a tunable diode laser sensor for measurements of gas turbine exhaust temperature. Applied Physics B 82: 469-478.

9. Sumizawa $\mathrm{H}$, Yamada $\mathrm{H}$, Tonokura $\mathrm{K}$ (2010) Real-time monitoring of nitric oxide in diesel exhaust gas by mid-infrared cavity ring-down spectroscopy. Applied Physics B 100: 925-931.

10. Anderson TN, Lucht RP, Priyadarsan S, Annamalai K, Caton JA (2007) In situ measurements of nitric oxide in coal-combustion exhaust using a sensor based on a widely tunable external-cavity GaN diode laser. Applied Optics 46: 3946-3957.

11. Magnuson JK, Anderson TN, Lucht RP (2008) Application of a diode-laserbased ultraviolet absorption sensor for in situ measurements of atomic mercury in coal-combustion exhaust. Energy and Fuels 22: 3029-3036.

12. Kasyutich VL, Holdsworth RJ, Martin PA (2009) In situ vehicle engine exhaust measurements of nitric oxide with a thermoelectrically cooled. Journal of Physics: Conference Series 157: 012006.

13. Wang F, Cen KF, Li N, Jeffries JB, Huang QX, et al. (2010) Two-dimensional tomography for gas concentration and temperature distributions based on tunable diode laser absorption spectroscopy. Meas Sci Technol 21: 4.

14. Ma L, Cai W (2008) Numerical investigation of hyperspectral tomography for simultaneous temperature and concentration imaging. Applied Optics 47: $3751-3759$.

15. Wright P, Terzijaa N, Davidsona JL, Garcia-Castillo S, Garcia-Stewart C et al. (2010) High-speed chemical species tomography in a multi-cylinder automotive engine. Chemical Engineering Journal 158: 2-10.
16. Deguchi Y, Yasui D, Adachi A (2012) Development of 2D temperature and concentration measurement method using tunable diode laser absorption spectroscopy. Journal of Mechanics Engineering and Automation 2: 543549 .

17. Deguchi Y, Kamimoto T, Kiyota Y, Choi D, Shim J (2013) Real-time 2D concentration and temperature measurement method using CT tunable diode laser absorption spectroscopy. Proceedings of WCIPT 7: 4.

18. Rothman LS, Gordon IE, Barbe A, Chris Benner D, Bernath PF, et al. (2009) The HITRAN2008 molecular spectroscopic database Journal of Quantitative Spectroscopy \& Radiative Transfer 110: 533-572.

19. Nelder JA, Mead RA (1965) Simplex method for function minimization. The Computer Journal 7: 308-313. 